\title{
Biospecimen Distribution Object
}

National Cancer Institute

\section{Source}

National Cancer Institute. Biospecimen Distribution Object. NCI Thesaurus. Code C45270.

A dimension table that lists the material distributed. This includes: ITEM_TYPE, ITEM_ID, ITEM_QUANT, and ITEM QUANT_UNIT. (caTISSUE) 